[DDI: 10.24214/jchps.A.9.3.15160]

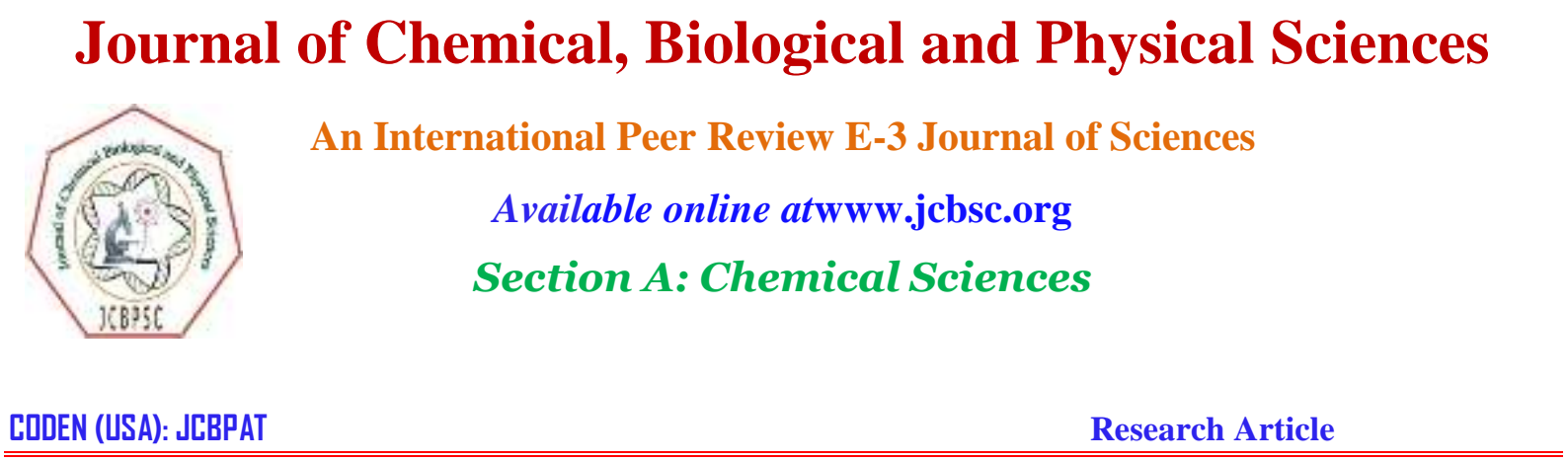

\title{
Kinetic of Crystal growth of Calcium oxalate monohydrate film coated quartz crystal microbalance electrode in presence of Trizma
}

\author{
Ahmed H. Mangood, ${ }^{1}$ Heba A. El-Shekheby, ${ }^{1, *}$ Naema S. Mostafa, ${ }^{1}$ El-Zeiny \\ M. Ebeid, 2,3 and Salem M. Hamza. ${ }^{1}$ \\ ${ }^{1}$ Department of Chemistry, Faculty of Science, Menoufia University, Shebin El-Kom,. \\ ${ }^{2}$ Department of Chemistry, Faculty of Science, Tanta University, Egypt. \\ ${ }^{3}$ Misr University for Science and Technology (MUST), 6th October City, Egypt
}

Received: 14 April 2019; Revised: 01 May 2019; Accepted: 12 May 2019

\begin{abstract}
Quartz crystal microbalance (QCM) apparatus has been used to study the kinetics of growth of calcium oxalate monohydrate $(\mathrm{COM})$ in aqueous solution. The reaction has been followed the diffusion mechanism at room temperature. The reaction carried in the presence of 2-amino-2-hydroxymethyl-1,3-propanediol (Trizma). The rate of crystallization of COM has been increased in presence of successive addition of this additive. The data obtained has been interpreted in the light of complexation phenomena.

Keywords: Crystal growth, calcium oxalate monohydrate, Trizma, Quartz crystal microbalance and Sauerbrey equation.
\end{abstract}

\section{INTRODUCTION}

Today, crystals are the pillars of modern technology. Without crystals, there would be no electronics industry, no photonics industry, no fibre-optic communications, very little modern optical equipment 
and some very important gaps in conventional production engineering. In the past few decades, there has been a growing interest in crystal growth process, particularly in view of the increasing demand of materials for technological applications ${ }^{[1]}$.

Modern technology requires physicists, chemists, electrical engineers, metallurgists and crystal growers to assist each other at many levels. Crystal growth is a vital and fundamental part of materials science and engineering, since crystals of suitable size and perfection are required for fundamental data acquisition and for practical devices such as detectors, integrated circuits and for other applications ${ }^{[1]}$. The formation of sparingly soluble salts from aqueous solutions and their dissolution has attracted broad research interest ${ }^{[2]}$.

Oxalates are the main inorganic components in pathological deposits and play a key role, in the formation of ordinary stones ${ }^{[3]}$. Calcium Oxalate $(\mathrm{CaOx})$ is one of the most abundant biominerals in superior plants ${ }^{[4]}$ and represents the most abundant inorganic compound found in mammal urinary calculi ${ }^{[5]}$. Formation of stones in urinary tract is one of the oldest diseases suffered by humans. There are mainly four types of calculi. A bout $75 \%$ of stones existed as containing, calcium oxalate or calcium oxalate mixed with calcium phosphate ${ }^{[6]}$. COM is the most stable thermodynamically and it is frequently found in human kidney stone (HKS) ${ }^{[7]}$. The presence of non-constituent ions or molecules may affect the rate of crystal growth or dissolution of COM crystals. The role of organic compounds in the formation of biomaterials remains largely unknown ${ }^{[8]}$.

Quartz crystal microbalances (QCM) Systems are applied routinely by biologists and biochemists to obtain information about processes such as: protein adsorption/desorption [9], cell adhesion ${ }^{[10]}$, Protein-protein interaction ${ }^{[11]}$, Degradation of polymers, biofouling and biofilm formation ${ }^{[12]}$, drug analysis ${ }^{[13]}$ and DNA Biosensors ${ }^{[14]}$. QCM is extremely sensitive to mass change, which is extensively employed in gas analysis since King first introduced in $1964{ }^{[15]}$. Sauerbrey ${ }^{[16]}$ was the first to recognize the potential usefulness of the Quartz Crystal Microbalance (QCM) technology and demonstrate the extremely sensitive nature of these piezoelectric devices towards mass changes at the surface of QCM electrodes ${ }^{[16]}$.

The mass of the film $(m)$ can be monitored as in equation (1) by measuring the oscillating frequency change $(\Delta f)$ of a quartz crystal and using the well-known Sauerbrey equation as shown in equation (2) [16].

$$
\begin{gathered}
\Delta f=-\mathrm{C}_{f} \cdot \Delta \mathrm{m} \\
\Delta f=-\left(\frac{2 f_{\circ}^{2}}{\sqrt{\rho_{Q} \mu_{Q}}}\right) m
\end{gathered}
$$

Where: $\Delta \mathrm{f}$ is the observed frequency change $(\mathrm{Hz})$;

$\Delta \mathrm{m}$ is the change in mass per unit area $\left(\mathrm{g} / \mathrm{cm}^{2}\right)$;

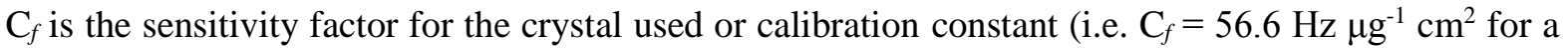
$5 \mathrm{MHz}$ AT-cut quartz crystal at room temperature,

$f_{\mathrm{o}}(\mathrm{Hz})$ is the natural frequency of the quartz crystal and $\rho_{\mathrm{Q}}$ is the quartz density $\left(2.649 \mathrm{~g} / \mathrm{cm}^{3}\right)$, and $\mu_{\mathrm{Q}}$ is the shear modulus $\left(2.947 \times 10^{10} \mathrm{~N} / \mathrm{m}^{2}\right)^{[16]}$. 
When the surface of a quartz crystal electrode is coated with a sensitive coating, capable of interacting with the environment of interest, it is possible to construct a sensitive sensor to the component under investigation. The selection of sensitive coating is a critical task in the design and performance of chemical QCM sensors ${ }^{[17]}$. Polymers are widely used as chemically sensitive coating materials on quartz crystal electrodes and are particularly suitable for detecting VOCs, because of the ability of the polymer to sorb vapor reversibly ${ }^{[18,19]}$. Recently, the polyaniline (PANI) film coating on the surface of gold electrodes of a QCM was developed by Ayad et al. for the determination of phosphoric acid ${ }^{[20]}$ and as a pH sensor based on aniline-anthranilic acid copolymer films ${ }^{[21]}$.

The kinetics of calcium sulfate dihydrate spontaneous precipitation in super-saturation solutions for temperatures ranging between 20 and $70{ }^{\circ} \mathrm{C}$ was investigated. The quartz crystal microbalance technique (QCM) was used. From measurements of the induction period for gypsum nucleation, interfacial tension was found to be 48.5 and $46.2 \mathrm{~mJ} \cdot \mathrm{m}^{2}$ at 20 and $70{ }^{\circ} \mathrm{C}$, respectively. The dependence of the induction period on temperature determined the activation energy, which ranged from 71 to 51 $\mathrm{kJ} . \mathrm{mol}^{-1}$ for the super-saturation range between 2.5 and 11. This work demonstrates that the QCM is a very attractive instrument to identify precipitation mechanisms and to measure the amount of the deposited crystals ${ }^{[22]}$.

In the present work an attempt to study the rate and mechanism of crystal growth of COM crystals in the absence and the presence of different concentration of Trizma using QCM technique.

\section{MATERIALS AND METHODS}

Calcium chloride $\left(\mathrm{CaCl}_{2}\right)$ and sodium oxalate $\left(\mathrm{Na}_{2} \mathrm{C}_{2} \mathrm{O}_{4}\right)$ (purchased from Sigma-Aldrich) were used to prepare seed crystals. Trizma (2-amino-2-hydroxymethyl-1, 3-propanediol) was proposed by Baek and Yoon procedure, as shown in Scheme (1) ${ }^{[23]}$. All solutions were prepared with deionized water of high quality (conductivity $<0.1 \mu \mathrm{S} \mathrm{cm}^{-1}$ ).

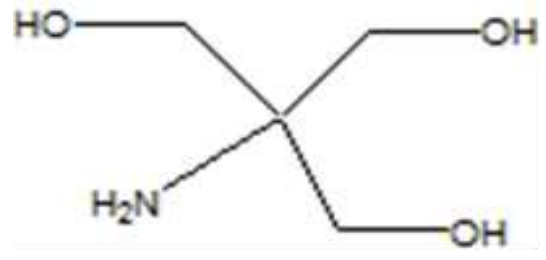

Scheme (1) Trizma (2-amino-2-hydroxymethyl-1,3-propanediol)

One liter of $0.1 \mathrm{M}$ calcium chloride solution was added to one liter of $0.1 \mathrm{M}$ sodium oxalate solution at $298{ }^{\circ} \mathrm{K}$ at a rate of $300 \mathrm{ml} / \mathrm{hr}$. The mixture was constantly stirred for one week and then the seed crystals were aged for one month, then, filtered and washed further with deionized distilled water to remove surface contamination due to chloride and oxalate ions and this process was repeated several times The prepared seed was dried at $40{ }^{\circ} \mathrm{C}{ }^{[24]}$. The seed crystal was confirmed as COM by Energy Dispersive X-ray Spectroscopy (EDX) and scanning electron microscope (SEM). The specific surface area of the crystals was $3.73 \mathrm{~m}^{2} / \mathrm{g}$ measured by Multi-point BET nitrogen adsorption.

Crystal growth experiments using QCM technique were made as the following: First, COM seed films are deposited onto the gold electrode of QCM. Then definite concentrations from $3 \times 10^{-4}$ to $9 \times 10^{-4}$ mole. $\mathrm{L}^{-1} \mathrm{CaCl}_{2}$ and from $3 \times 10^{-4}$ to $9 \times 10^{-4}$ mole. $\mathrm{L}^{-1} \mathrm{Na}_{2} \mathrm{C}_{2} \mathrm{O}_{4}$ (equi-molar) without/with $\left(6 \times 10^{-4}\right.$ mole. $\mathrm{L}^{-1} \mathrm{Na}_{2} \mathrm{C}_{2} \mathrm{O}_{4} / \mathrm{CaCl}_{2}$ ) definite concentration of additive (Trizma) ranging from $3 \times 10^{-7}$ to $9 \times 10^{-7}$ 
mole. $\mathrm{L}^{-1}$ were added slowly to the polyethylene cell and kept unstirred. The mass per unit area of the COM film, $\mathrm{m}\left(\mathrm{g} \mathrm{cm}^{-2}\right)$, grown on the gold surface of the crystal was determined from the change in the crystal resonance frequency from Sauerbrey equation. The frequency decreases linearly with increasing mass deposited on the electrode. The time dependence of frequency was recorded at room temperature $\left(25^{\circ} \mathrm{C}\right)$ for each solution.

\section{RESULTS AND DISCUSSION}

From scanning electron microscopic (SEM) measurements, we can see that there is a rough and uneven landscape which water able to freely flow through voids within the COM structure which is pronounced in the (Figure 1). By measuring the elements in the crystal of COM, the data from (figure 2) has been shown by EDX. So, COM structure elucidated using SEM and EDX.

The COM film coating on to the electrode of QCM was exposed to different concentration of working solutions $\left(\mathrm{CaCl}_{2} / \mathrm{Na}_{2} \mathrm{C}_{2} \mathrm{O}_{4}\right)$ from $3 \times 10^{-4}$ to $9 \times 10^{-4}$ mole. $\mathrm{L}^{-1}$ and to different concentration of Trizma solutions from $3 \times 10^{-7}$ to $9 \times 10^{-7}$ mole. $L^{-1}$ as additive. In absence of additive the frequency changes due to COM film deposition onto the gold electrode of the QCM. In presence of additive the frequency changes due to the adsorption of Trizma solution on the film of COM and formation of complex as a function of the growth time were recorded.

The frequency of the quartz crystal decreased due to the deposition of the working solutions in absence of additive and due to the adsorption of the Trizma additive into the electrode according to Sauerbrey equation (2). The time dependence of frequency shift $(\Delta f)$, which corresponds to the deposition of the working solutions and adsorbed Trizma molecules, was measured at different concentrations in absence and presence of additive. Generally at a specific concentration, $\Delta f$ increases linearly with time up to steady state condition.

From Sauerbrey equation (2), the plots of the yield (mass (m)) of COM seed film deposition onto the gold electrode of QCM against time illustrated in (Figure 3). This is for solutions of equi-molar ratio of $\mathrm{CaCl}_{2} / \mathrm{Na}_{2} \mathrm{C}_{2} \mathrm{O}_{4}$ that is from $3 \times 10^{-4}$ to $9 \times 10^{-4}$ mole. $\mathrm{L}^{-1}$.

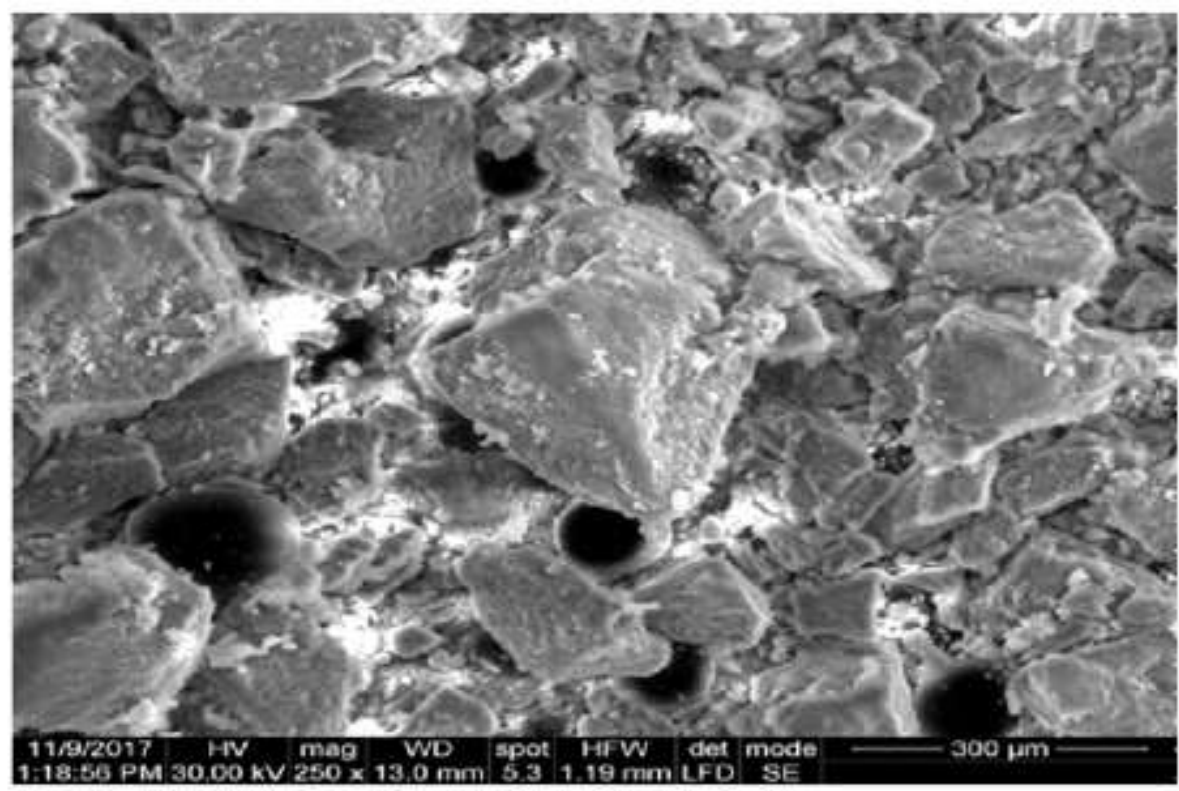

Figure 1: SEM of COM seed. 


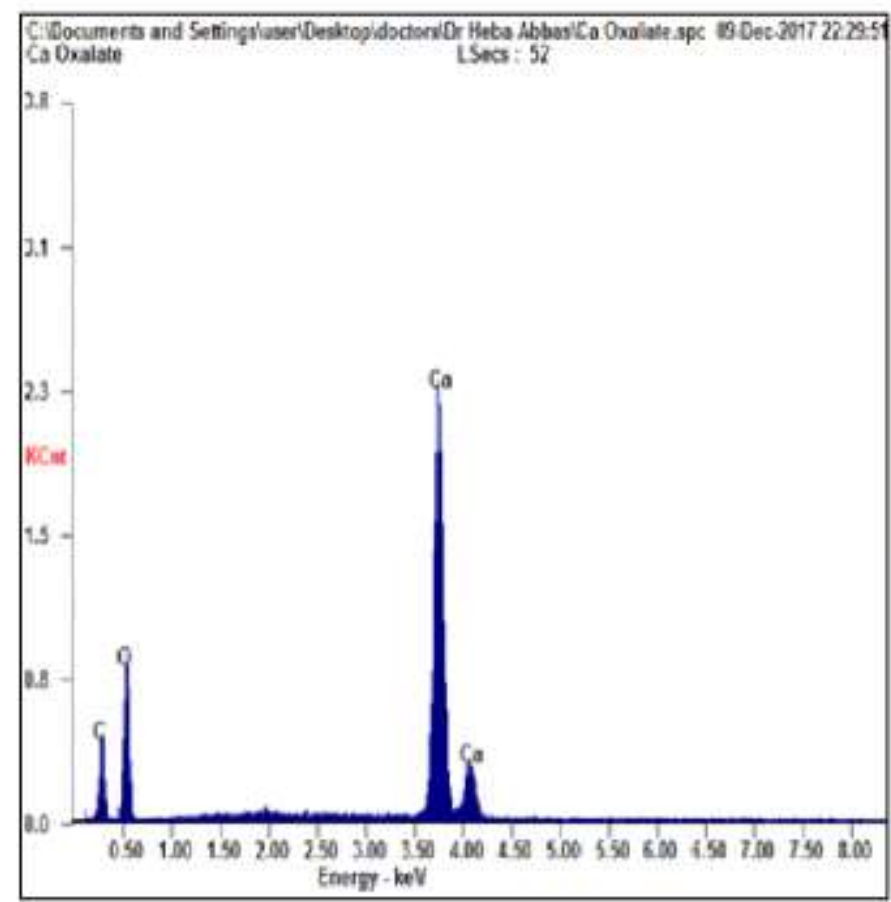

\begin{tabular}{|l|c|c|}
\hline Element & Wt $\%$ & At $\%$ \\
\hline$C K$ & 23.75 & 35.11 \\
\hline$O K$ & 46.66 & 51.78 \\
\hline$C a K$ & 29.58 & 13.11 \\
\hline
\end{tabular}

Figure 2: EDX of COM seed stone

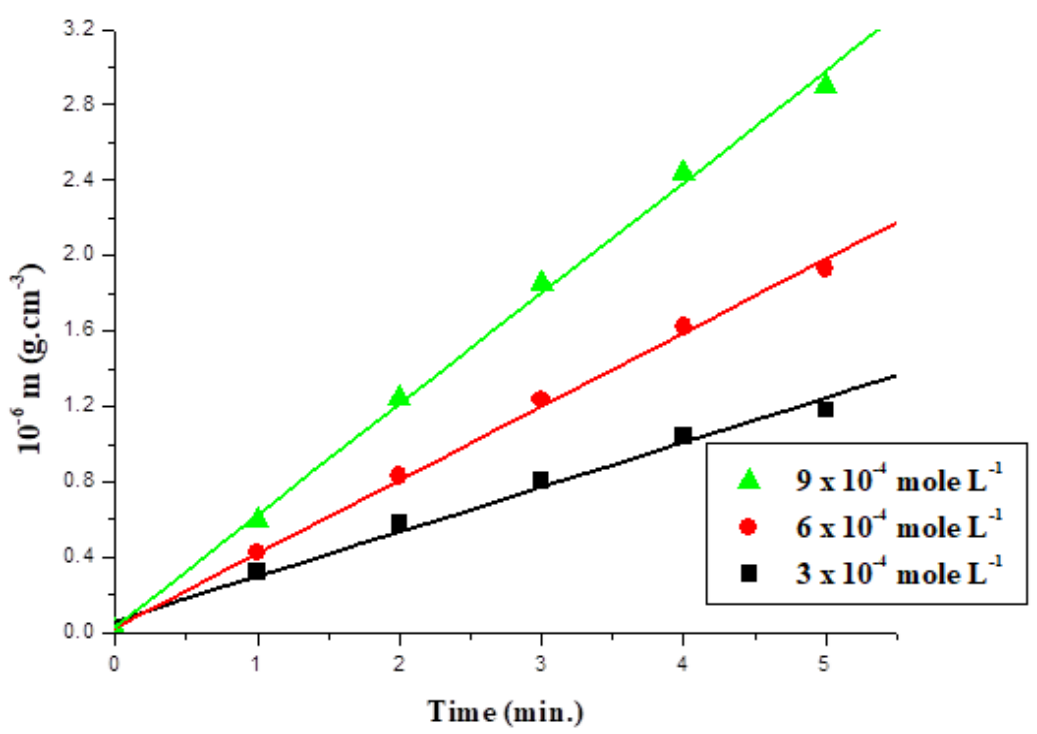

Figure 3: Time dependence of mass during the COM seed film formation for the solution of equimolar ratio $\mathrm{CaCl}_{2} / \mathrm{Na}_{2} \mathrm{C}_{2} \mathrm{O}_{4}$ ranging from $3 \times 10^{-4}$ to $9 \times 10^{-4}$ mole. $\mathrm{L}^{-1}$. 
The yield of the COM seed film increases with successive addition of Trizma solution, as illustrated in (Figure 4), due to formation of coordination bond between Trizma and COM which may lead to formation of complex and adsorb on the surface of COM film.

The rates of growth of calcium oxalate monohydrate (COM) seed film in absence and presence of different concentration of Trizma additive is easily calculated from the slope of the mass-time relation.

(Figure 5a,b) shows the plot of the growth rate of COM seed film in absence and presence of different concentration of Trizma ranging from $3 \times 10^{-7}$ to $9 \times 10^{-7}$ mole. $\mathrm{L}^{-1}$ which used as promoter or accelerator for growth of COM. This behavior has been observed previously by Rizkalla who was found at low concentration levels of chromate and ferrocyanide anions additives, the rate of growth of barium sulfate enhanced ${ }^{[25]}$. In other previous study the nucleation of calcium oxalate crystals by albumin was founded as stronger promoter for calcium oxalate nucleation ${ }^{[26]}$ and by Golovanova was found that the valine amino acid promote the crystallization of calcium oxalate monohydrate ${ }^{[27]}$.

By plotting - $\log \mathrm{R}$ against - Log conc. as shown in (Figure 6), we obtained a straight line with slope equal to 0.84 in case of absence of additive (a) and 0.52 in presence of additive $\left(a_{1}\right)$ that means the reaction has been followed the diffusion mechanism in both cases.

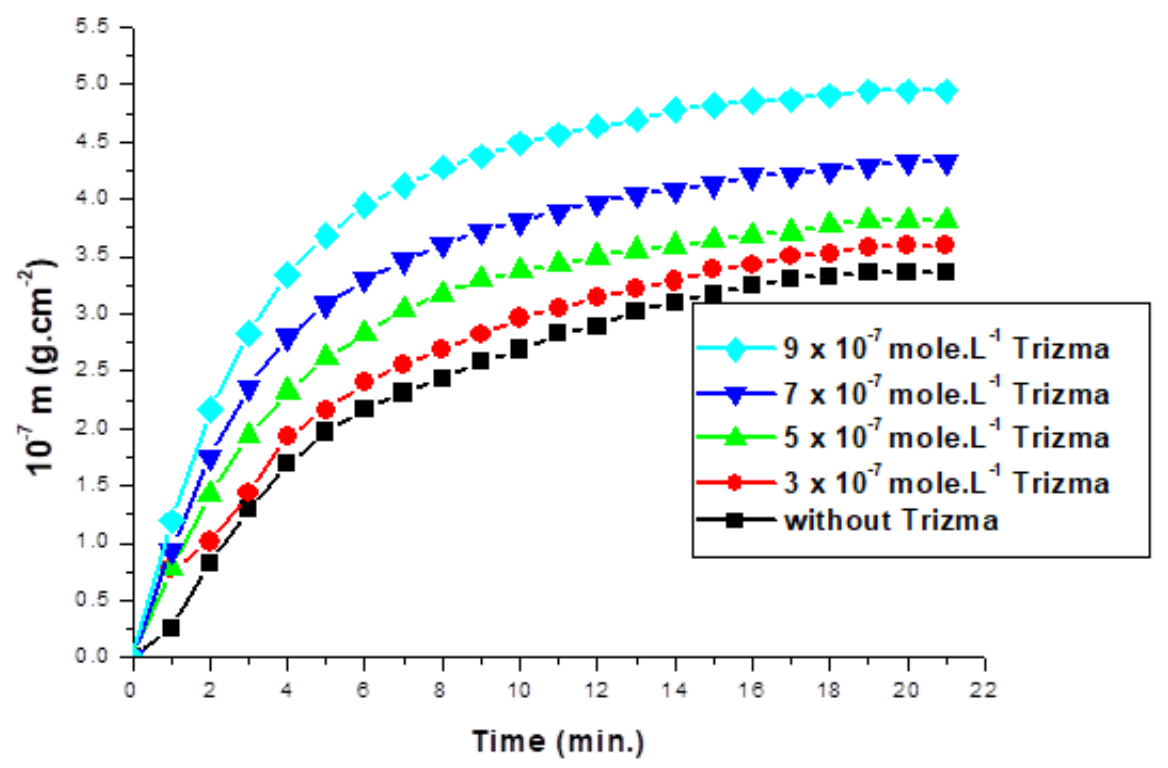

Figure 4: Time dependence of mass during the COM seed film formation for the solution of equi-molar ratio $\mathrm{CaCl}_{2} / \mathrm{Na}_{2} \mathrm{C}_{2} \mathrm{O}_{4}=6 \times 10^{-4}$ mole.L $\mathrm{L}^{-1}$ in presence of $3 \times 10^{-7}$ to $9 \times 10^{-7}$ mole. $\mathrm{L}^{-1}$ Trizma as additive. 


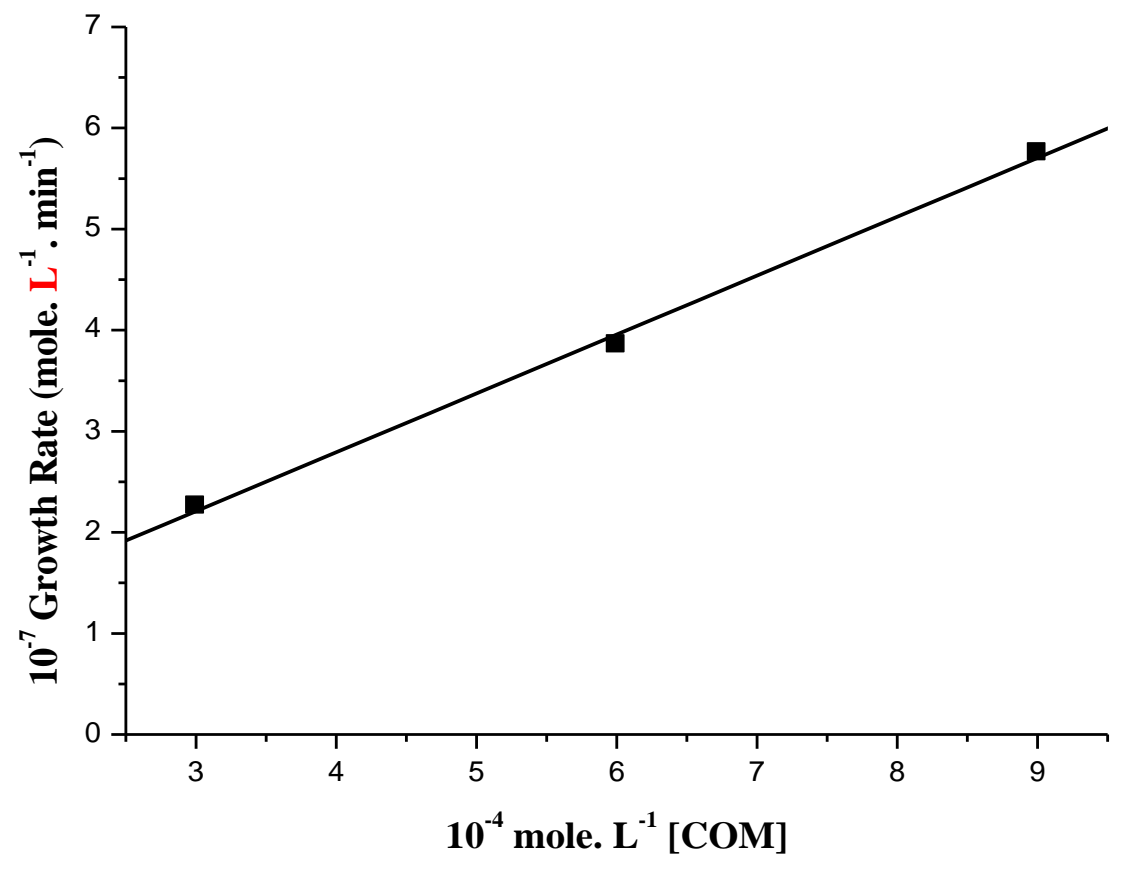

Figure 5a: Growth rate of COM film in absence of additive.

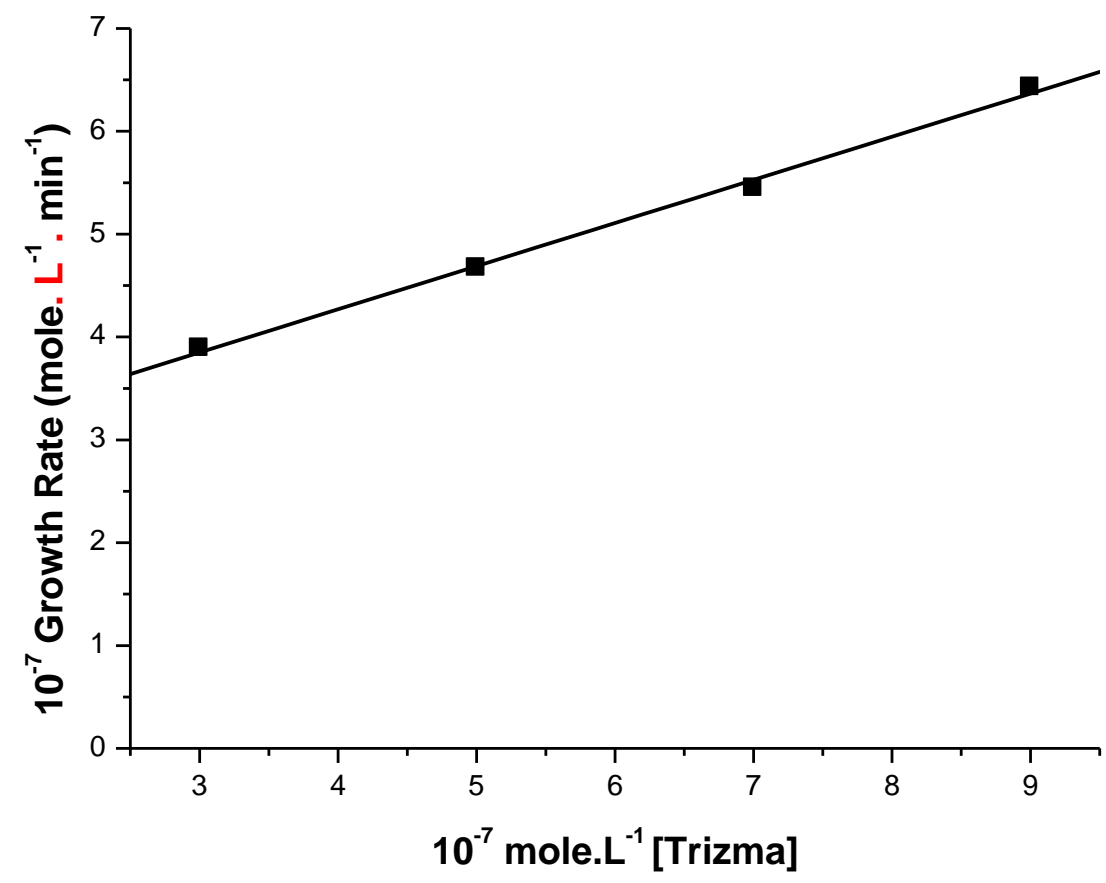

Figure 5b: Growth rate of COM film as a function of different concentration of Trizma ranging from $3 \times 10^{-7}$ to $9 \times 10^{-7}$ mole. $\mathrm{L}^{-1}$. 


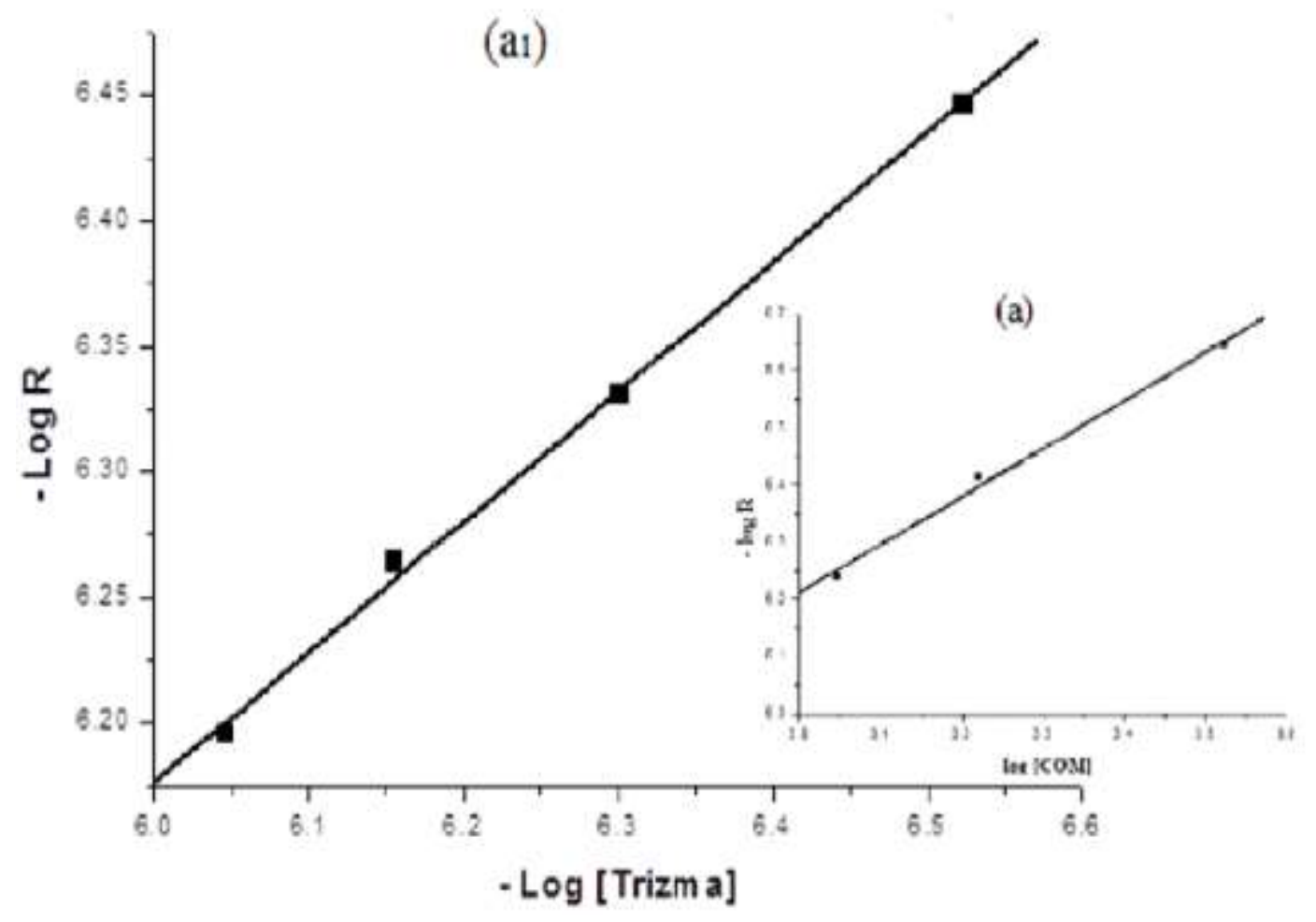

Figure 6: Relation between $-\log$ conc. against $-\log \mathrm{R}$ without additive (a) and with additive $\left(\mathrm{a}_{1}\right)$.

\section{CONCLUSION}

2-amino-2-hydroxymethyl-1,3-propanediol (Trizma) has been used as additive for crystallization of calcium oxalate monohydrate. The addition of this additive promotes the crystallization rate. The mechanism of reaction in absence and presence of this additive has not varied. Quartz crystal microbalance $(\mathrm{QCM})$ has been used for this study at room temperature.

\section{REFERENCES}

1. B. Subashini and Mrs.Geetha, Introduction to Crystal Growth Techniques, J. Engineering and Tech., 2017, 3(5), 1.

2. P. G. Koutsoukos, A. N. Kofina and D. G. Kanellopoulou, Solubility of salts in water: Key issue for crystal growth and dissolution processes, Pure Appl. Chem.; 2007, 79(5), 825.

3. D. J. White and G. H. Nancollas, The kinetics of dissolution of calcium oxalate monohydrate: a constant composition method, J. Cryst. Growth, 1982, 57, 267.

4. P. V. Monje and E. J. Baran, Characterization of calcium oxalates generated as biominerals in cacti, Plant Physiol., 2002, 128, 707. 
5. A. Neira-Carrillo, Formation of kidney stones of calcium oxalate in mammals, Av. Cienc. Vet., 2010, 25.

6. E. L. Priem and C. Frondel, Studies in urolithiasis; the composition of urinary calculi, J. Urol., 1947, 57, 949.

7. A. L. Rodgers, D. Webber, R. Ramsout and M. D. Gohel, Herbal preparations affect the kinetic factors of calcium oxalate crystallization in synthetic urine: Implication for kidney stone therapy, J. Urol.; 2014, 42, 221.

8. S. Whipps, S. R. Khan, F. Jeffrey, O. Palko, K. Backov and D. R. Talham, Precipitation of calcium oxalate monohydrate at phospho-lipid monolayers, J. Crys. Growth, 1998, 192, 243.

9. F. Hook, M. Rodahl, B. Kasemo and P. Brzezinski, Structural changes in hemoglobin during adsorption to solid surfaces: effects of $\mathrm{pH}$, ionic strength and ligand binding, Proc. Natl. Acad. Sci. USA; 1998, 95, 12271.

10. C. Fredriksson, S. Kihlman, M. Rodahl and B. Kasemo, The Piezoelectric Quartz crystal Mass and Dissipation Sensor: A means of studyinng Cell adhesion, Langmuir, 1998, 19, 248.

11. A. Cans, F. Hook, O. Shupliakov, A. G. Ewing, P. S. Eriksson, L. Brodin and O. Orwar, Measurement of the Dynamics of Exocytosis and Vesicle Retrieval at Cell Populations Using a QCM, Anal. Chem., 2001, 73(24), 5805.

12. C. A. Keller and B. Kasemo, Surface Specific Kinetics of Lipid Vesicle Adsorption Measured with a QCM, J. Biophys., 1998, 75, 1397.

13. W. Wanzhi, H. Changwen, Z. Wenhong and Y. Shouzhuo, Selective pharmaceutical analyis technique with sensitive piezoelectric quartz sensors, Anal. Lett, 1993, 26(11), 2371.

14. S. Storri, T. Santoni and M. Mascini, Anal. Lett., A piezoelectric biosensor for DNA hybridization detection, 1998, 31(11),1795.

15. W. H. King, Piezoelectric sorption detector, Anal. Chem., 1964, 36 (9), 1735.

16. G. Sauerbrey, The use of quartz oscillators for weighing thin layers and for microweighing, Z. Phys., 1959, 155, 206.

17. R. Patel, R. Zhou, K. Zinszer and F. Josse, Real-time detection of organic compounds in liquid environments using polymer-coated thickness shear mode quartz resonators, Anal. Chem., 2000, 72, 4888.

18. N. Levit, D. Pestov and G. Tepper, High surface area polymer coatings for SAW-based chemical sensor applications, Sensors and Actuators, B: chemical, 2002, 82, 241.

19. L. X. Sun and T. Okada, Studies on interactions betweenNafion and organic vapours by quartz crystal microbalance, J. Membr. Sci., 2001, 183, 213.

20. M. M. Ayad, N. A. Salahuddin, M. O. Al-Ghayesh and R. M. Issa, Phosphoric acid and pH sensors based on polyaniline films, Thin Solid Films, Current Applied Phys., 2010, 10(1), 235 .

21. M. M. Ayad, N. A. Salahuddin and M. O. Al-Ghayesh, pH and aniline-anthranilic acid copolymer films using quartz crystal microbalance and electronic absorption spectroscopy, Polym. Adv. Technol., 2008, 19, 1142. 
22. F. Alimi, H. Elfil and A. Gadrib, Kinetics of the precipitation of calcium sulfate dihydrate in a desalination unit, Desalination, 2003, 158, 9.

23. J. I. Baek and J. H. Yoon, Solubility of Carbon Dioxide in Aqueous Solutions of 2-Amino-2methyl-1,3-propanediol, J. Chem. Eng. Data, 1998, 43(4), 635.

24. N. S. Yehia, R. M. Issa and N. Y. Shalaby, The effect of some organic compounds in the dissolution of calcium oxalate monohydrate crystals, Egypt. J. Chem., 2009, 52(4), 477.

25. E. N. Rizkalla, Kinetics of the crystallisation of barium sulphate: Effect of additives, stirring rate and barium: sulphate ratio on the rate of precipitation, J. Chem. Soc., Faraday Trans. 1, $1983,79,1857$.

26. C. Cerini, S. Geider, B. Dussol, C. Hennequin, M. Daudon, S. Veesler, S. Nitsche, R. Boistelle, P. Berthezene, P. Dupuy, A. Vazi, Y. Berland, J. Dagorn and J. Verdier, Nucleation of calcium oxalate crystals by albumin: Involvement in the prevention of stone formation, Kideny Inter., 1999, 55, 1776.

27. O. A. Golovanova, Y. O. Punin, A. R. Izatulina, V. V. Korol'kov, Crystallization of calcium oxalate monohydrate in the presence of amino acids: Features and regularities, J. Struct. Chem., 2014, 55(7), 1356.

\section{Corresponding author: Heba A. El-Shekheby;}

Department of Chemistry, Faculty of Science, Menoufia University,

Shebin El-Kom, Egypt. Heba.chem@yahoo.com. +2 01064922475

Online publication Date: 12 .05.2019 